\title{
Mass-Analyzed Threshold Ionization Spectroscopy of $o-, m$-, and $p$-Methylaniline Cations: Vicinal Substitution Effects on Electronic Transition, Ionization, and Molecular Vibration
}

\author{
J. L. Lin,,+ K. C. Lin,,+ \\ Institute of Atomic and Molecular Sciences, Academia Sinica, P.O. Box 23-166, 1 Section 4, Roosevelt Road, \\ Taipei 106, Taiwan, Republic of China, and Department of Chemistry, National Taiwan University, \\ Taipei 106, Taiwan, Republic of China
}

Received: February 20, 2002; In Final Form: May 3, 2002

\begin{abstract}
We have applied two-color resonant two-photon mass analyzed threshold ionization (MATI) spectroscopy to investigate the ionic properties of the structural isomers of methylaniline. The adiabatic ionization energies of $o-, m-$, and $p$-methylanilines have been determined to be $61002 \pm 5,61059 \pm 5$, and $60160 \pm 5 \mathrm{~cm}^{-1}$, respectively. These vibrationally resolved spectra provide information about the active normal vibrations of the corresponding cations. The observed spectral features have been successfully assigned on the basis of comparison with the results from ab initio and density functional calculations and experimental data available in the literature. The results suggest that both the nature of the substitutents and the relative location in the ring can influence the electronic transition, ionization, and molecular vibration for these structural isomers.
\end{abstract}

\section{Introduction}

Ion spectroscopy is one of the most important methods to provide detailed information about the ionic properties of molecular species. ${ }^{1}$ For disubstituted benzenes, the nature and the relative location of the two groups can lead to distinct molecular properties as well as reactivity in chemical reactions. ${ }^{2,3}$ The ionization energy (IE) is one of the most important molecular properties when one concerns photophysics and photochemistry involving thermochemical cycles. In principle, this value is unique for each molecular species provided that it can be measured with a high precision method. However, they may differ by only a few tens to a few hundreds of wavenumbers for structural isomers. ${ }^{4-6}$ Owing to the lack of accuracy in the experimental methods applied, the reported IEs of $o^{-}, m^{-}$, and $p$-methylanilines (henceforth, OMA, MMA, and PMA) fall into the ranges of 7.44-7.75, 7.50-7.75, and 7.24-7.60 eV, respectively. ${ }^{7}$ The investigations on some detailed ionic properties among these structural isomers require a high-resolution spectroscopic method.

Since its development, zero kinetic energy (ZEKE) photoelectron spectroscopy has proved to be a powerful technique for recording high-resolution spectra of molecular ions. ${ }^{8}$ The later developed mass-analyzed threshold ionization (MATI) technique involves detection of so-called ZEKE ions rather than electrons. ${ }^{9}$ Although it suffers from low signal, MATI spectroscopy can provide unambiguous mass information with a comparable spectral resolution as that of ZEKE spectroscopy. ${ }^{10}$ These high resolution ion spectroscopic methods are particularly useful for the investigations that require a spectral resolution as high as a few wavenumbers, such as the isotope effects on the transition energy, IE, and molecular vibrations as well as the site-specific electronic transition. ${ }^{11-13}$

In methylanilines, the $\mathrm{CH}_{3}$ substituent interacts with the nearby $\pi$ system via hyperconjugation, whereas the $\mathrm{NH}_{2}$ shares

\footnotetext{
* Corresponding author. Tel: (886)2-23628236. Fax: (886)2-23620200. E-mail: wbt@ sinica.edu.tw.

Academia Sinica.

National Taiwan University.
}

its lone-pair electrons with the p electrons in a ring. Previous spectroscopic and theoretical studies have offered information about the structures, symmetry, and vibrations of OMA, MMA, and PMA in the $S_{0}$ and $S_{1}$ states. ${ }^{14-22}$ Detailed investigations on the ionic properties of these isomers are still not rich. Recently, Fujii and co-workers have applied pulsed field ionization zero kinetic energy (PFI-ZEKE) spectroscopy to investigate the internal rotation of the $\mathrm{CH}_{3}$ group of OMA and MMA in the cationic ground state. ${ }^{23}$ Nevertheless, the precise adiabatic IEs of the three structural isomers of methylaniline, the vibrations, and other properties of the corresponding cations still remain unexplored.

In this paper, we report the MATI spectra of OMA, MMA, and PMA by using two-color resonant two-photon excitation MATI spectroscopy. These spectra were recorded by ionizing through various intermediate levels in the $S_{1}$ states of the selected species. Detailed spectral analyses yield the precise IEs of these structural isomers and the active vibrations of the corresponding cations. By comparing these new experimental data among the structural isomers, one learns the vicinal substitution effects on electronic transition, ionization, and molecular vibration. We have also performed ab initio and density functional theory (DFT) calculations to support the experimental findings.

\section{Experimental and Computational Details}

2.1. Experimental Method. The experiments reported in this paper were performed with a laser-based TOF mass spectrometer as described in our previous publication. ${ }^{4}$ All of the OMA, MMA, and PMA samples were purchased from Aldrich Corp. with rated purity $99 \%$ and used without further purification. The chemical samples were heated to provide sufficient vapors, seeded into 2 bar of helium, and expanded into the vacuum through a pulsed valve with a $0.15 \mathrm{~mm}$ diameter orifice. The molecular beam was collimated by a skimmer located $15 \mathrm{~mm}$ downstream from the nozzle orifice. During the experiments, the gas expansion and the ionization regions were maintained at a pressure of about $1 \times 10^{-3}$ and $1 \times 10^{-5} \mathrm{~Pa}$, respectively. 
The two-color resonant two-photon excitation/ionization process was initiated by utilizing two independent tunable UV laser systems controlled by a pulse delay generator (Stanford Research Systems, DG 535). The excitation source is a Nd: YAG pumped dye laser (Quanta-Ray GCR-3/PDL-3; Rhodamin $590,610,620$, and 640 dyes) with bandwidth $\leq 0.3 \mathrm{~cm}^{-1}$. The visible radiation is frequency doubled to produce UV radiation. The ionization UV laser (Lambda-Physik, ScanmateUV with BBO-III crystal; DCM and LDS 698, 722, and 765 dyes) was pumped by a frequency-doubled Nd:YAG laser (Quantel, Brilliant B). The wavelengths of both dye lasers were calibrated using a Fizeau-type wavemeter (New Focus 7711). The respective UV laser outputs were monitored with two separated photodiodes (Hamamatsu 1722S) and fed into a transient digitizer (LeCroy LT224). The two counter-propagating laser beams were focused and intersected perpendicularly with the skimmed molecular beam at $50 \mathrm{~mm}$ downstream from the nozzle orifice.

In the MATI experiments, both the prompt ions and the Rydberg neutrals were formed simultaneously in the laser and molecular beam interaction zone. A pulsed electric field of -1 $\mathrm{V} / \mathrm{cm}$ (duration $=10 \mu \mathrm{s}$ ) was switched on $\sim 0.74 \mu \mathrm{s}$ after the occurrence of the laser pulses to reject the prompt ions. After a time delay of $\sim 9.60 \mu$ s, a second pulsed electric field of +200 V/cm (duration $=10 \mu \mathrm{s}$ ) was applied to field-ionize the Rydberg neutrals. These threshold ions were then accelerated and passed a $1.0 \mathrm{~m}$ field-free region before being detected by a dual-stacked microchannel plate particle detector. The ion signal from the detector was collected and analyzed by a multichannel scaler (Stanford Research Systems, SR430). The multichannel scaler and the transient digitizer were interfaced to a personal computer. Mass spectra were accumulated at $1.2 \mathrm{~cm}^{-1}$ spacing for 300 laser shots. Composite optical spectra of intensity versus wavelength were then constructed from the individual mass spectra. As the detected ion signal is proportional to the photon intensities of the excitation and ionization lasers for a two-color two-photon process, the obtained optical spectra were normalized to the laser power in order to avoid spurious signals due to shot-to-shot laser fluctuation.

2.2. Computational Method. Ab initio and DFT calculations for predicting the structure parameters, energies, and vibrational frequencies were performed using the GAUSSIAN 98 program package. ${ }^{24}$ The IE was obtained as the difference in the zeropoint energies of the cation and the corresponding neutral. All calculated vibrational frequencies of the cations quoted in this paper were scaled by a factor of 0.95 to correct approximately for the errors stemming from basis set incompleteness and neglect of electron correlation and vibrational anharmonicity.

\section{Results}

The electronic spectra of OMA, MMA, and PMA near their respective $S_{1} \leftarrow S_{0}$ transitions have been reported. ${ }^{14-22}$ Detailed analyses on the spectral features show that the active motions of these species in the $\mathrm{S}_{1}$ state include the aromatic ring vibrations, the $\mathrm{CH}_{3}$ rotation, and the $\mathrm{NH}_{2}$ inversion. Concerning the bands corresponding to the internal rotation of the $\mathrm{CH}_{3}$ group, they appear to be relatively intense for OMA and MMA, but very weak for PMA. The well-resolved spectral features may be used as the fingerprints for molecular identification. It is known that the species selection as well as the vibronic state selection can be achieved by applying the two-color resonant two-photon excitation for successive exciation/ionization. ${ }^{1}$ This is accomplished by fixing the frequency of the first excitation laser at a particular fingerprint level in the $S_{1}$ state of the chosen

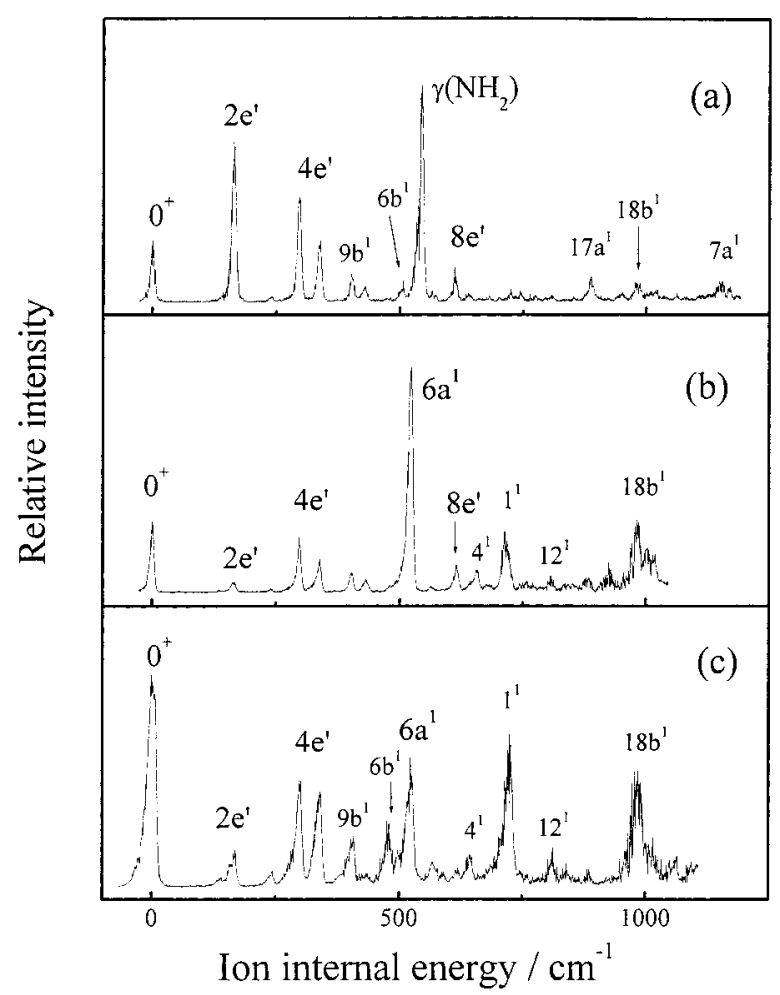

Figure 1. MATI spectra of OMA, recorded by ionizing via the (a) $\mathrm{S}_{1} 0^{\circ}$, (b) $\mathrm{S}_{1} 2 \mathrm{e}^{\prime}$, and (c) $\mathrm{S}_{1} 4 \mathrm{e}^{\prime}$ intermediate states.

species while tuning the frequency of the second laser across the ionization limit. The species selection is mostly useful for separating the impurities in the sample as well as selecting a desired conformational isomer. ${ }^{6,25,26}$ The MATI experiments with the vibronic state selection can provide information about the molecular geometry and symmetry of the cation. $6,11,12,27,28$ Since the signal resulting from the prompt ions is more than that from the threshold ions,, we always perform the 2C-R2PI experiments to locate the ionization threshold of molecular species before applying the MATI method for recording the threshold ion spectra. ${ }^{4-6,28}$ The main advantage of the MATI over the 2C-R2PI spectroscopic method is that it provides information about the active internal motions of the cation in addition to the precise adiabatic IE.

3.1. MATI Spectra of OMA. Figure 1 shows the MATI spectra of OMA recorded by ionizing through the vibrationless $0^{\circ}\left(34318 \mathrm{~cm}^{-1}\right)$ and the $\mathrm{CH}_{3}$ torsional $2 \mathrm{e}^{\prime}\left(34346 \mathrm{~cm}^{-1}\right)$ and $4 \mathrm{e}^{\prime}\left(34405 \mathrm{~cm}^{-1}\right)$ levels of the $\mathrm{S}_{1}$ state. The leftmost band in the spectrum results from the transition to the motionless cationic ground state. Since the cations are formed at an energy level that is slightly below the true ionization threshold, one should consider the high-energy side of these $0^{+}$bands for obtaining the adiabatic IE. ${ }^{29}$ Furthermore, in the MATI experiments it requires a small electric field $(-1 \mathrm{~V} / \mathrm{cm})$ to reject the prompt ions. This procedure introduces a lowering in the observed ionization threshold. The energy shift due to the Stark effect may be approximated to be $4.0 F^{1 / 2}$ when a pulsed electric field $F$ is applied. ${ }^{30}$ If the uncertainty in the laser photon energy, the spectral width, and the Stark shift were taken into account, the adiabatic IE of OMA is determined to be $61002 \pm 5 \mathrm{~cm}^{-1}$ $(7.5629 \pm 0.0006 \mathrm{eV})$, which is in good agreement with that reported in the literature. ${ }^{7}$ The Becke three-parameter with the PW91 correlation functional (B3PW91) calculations with the $6-311+\mathrm{G}^{* *}$ basis set yield a value of $59631 \mathrm{~cm}^{-1}(7.3929 \mathrm{eV})$, which deviates from the measured one by about $2.2 \%$. 
TABLE 1: Observed Bands $\left(\mathrm{cm}^{-1}\right)$ in the MATI Spectra of OMA and Possible Assignments ${ }^{a}$

\begin{tabular}{|c|c|c|c|c|}
\hline \multicolumn{3}{|c|}{ intermediate level in $S_{1}$} & \multirow[b]{2}{*}{ calcd } & \multirow{2}{*}{$\begin{array}{l}\text { assignment and } \\
\text { approximate } \\
\text { description }\end{array}$} \\
\hline $0^{0}$ & $2 \mathrm{e}^{\prime}$ & $4 \mathrm{e}^{\prime}$ & & \\
\hline $166(170)$ & 167 & $\begin{array}{l}170 \\
244\end{array}$ & $\begin{array}{l}142(170) \\
233\end{array}$ & $\begin{array}{l}2 \mathrm{e}^{\prime}, \mathrm{CH}_{3} \text { torsion } \\
10 \mathrm{~b}^{1}, \gamma \mathrm{CN}\end{array}$ \\
\hline $298(330)$ & 297 & 298 & $300(322)$ & $4 \mathrm{e}^{\prime}, \mathrm{CH}_{3}$ torsion \\
\hline 339 (347) & 339 & 340 & $(322)$ & $4 \mathrm{e}^{\prime}, \mathrm{CH}_{3}$ torsion \\
\hline 401 & 404 & 408 & 406 & $9 \mathrm{~b}^{1}, \beta \mathrm{CCH}_{3}$ \\
\hline 430 & $432(440)$ & $432(440)$ & 445 & $5 \mathrm{e}^{\prime}, \mathrm{CH}_{3}$ torsion \\
\hline 506 & & 480 & 477 & $6 \mathrm{~b}^{1}$, ring $\beta \mathrm{CCC}$ \\
\hline 544 & 523 & 524 & 548 & $\begin{array}{l}6 \mathrm{a}^{1}, \text { ring } \beta \mathrm{CCC} \\
\gamma \mathrm{NH}_{2}(\mathrm{wag})\end{array}$ \\
\hline 610 & 615 & 620 & $(625)$ & $8 \mathrm{e}^{\prime}, \mathrm{CH}_{3}$ torsion \\
\hline & 655 & 648 & 650 & $4^{1}$, ring $\gamma \mathrm{CCC}$ \\
\hline 725 & 715 & 724 & 695 & $1^{1}$, breathing \\
\hline & 809 & 813 & 807 & $12^{1}, \operatorname{ring} \beta \mathrm{CCC}$ \\
\hline 888 & & & 825 & $17 \mathrm{a}^{1}$, ring $\gamma \mathrm{CH}$ \\
\hline 981 & 986 & 986 & 999 & $18 \mathrm{~b}^{1}$, ring $\beta \mathrm{CH}$ \\
\hline 1148 & & & 1149 & $7 \mathrm{a}^{1}, v \mathrm{CCH}_{3}$ \\
\hline
\end{tabular}

${ }^{a}$ The experimental values are shifts from $61002 \mathrm{~cm}^{-1}$, whereas the calculated ones (scaled by 0.95 ) are obtained from the unrestricted B3LYP/6-311+G** calculations. $\nu, \beta$, and $\gamma$ represent stretching, inplane bending, and out-of-plane bending vibrations, respectively. The numbers in the parentheses are retrieved from ref 23.

The spectral features shifted from the $0^{+}$band are caused by the internal motions of the cation. It is found that many lowfrequency bands dominate in the spectra and are in very good agreement with those observed in the PFI-ZEKE experiments. ${ }^{23}$ Analyses show that they result from the $\mathrm{CH}_{3}$ internal rotation and have been well discussed previously. Here, we focus on the newly observed MATI bands related to the active vibrations of the aromatic ring of the OMA cation. Although the corresponding bands are relatively weak, they have a decent signalto-noise ratio. A key factor for this achievement is to minimize the signal resulting from the one-color R2PI processes. ${ }^{4}$ In the present MATI experiments, the intensities of the excitation and ionization laser outputs were adjusted in such a way that the ratio of the two-color to one-color R2PI signals was greater than 50:1. The respective pulse energies of the excitation and ionization lasers were kept at about 80 and $300 \mu \mathrm{J}$, respectively. The Varsanyi's numbering system ${ }^{31}$ was adopted to approximately describe the normal modes of benzene-like vibrations. The assignments to these MATI bands were made mainly on the basis of the unrestricted hybrid Becke three-parameter LeeYang-Parr (B3LYP) functional calculations using the 6-311+G** basis set and conformity with the experimental data of this molecule in the $\mathrm{S}_{0}$ and $\mathrm{S}_{1}$ states, as listed in Table 1. Briefly, the bands at $401,506,725,888,981$, and 1148 are tentatively assigned to the vibrations $9 \mathrm{~b}^{1}, 6 \mathrm{~b}^{1}, 1^{1}, 17 \mathrm{a}^{1}, 18 \mathrm{~b}^{1}$, and $7 \mathrm{a}^{1}$ of OMA in the cationic ground state, respectively. The active modes $9 \mathrm{~b}$ and $7 \mathrm{a}$ mainly involve the $\mathrm{CCH}_{3}$ in-plane bending and stretching vibrations, respectively. Mode $6 \mathrm{~b}$ represents the in-plane ring deformation, whereas $18 \mathrm{~b}$ and $17 \mathrm{a}$ stand for the in-plane and out-of-plane ring $\mathrm{CH}$ bending vibrations, respectively. The strong band at $544 \mathrm{~cm}^{-1}$ is tentatively assigned to the inversion vibration (or referred to as the wagging motion) of the amino group.

When the $\mathrm{S}_{1} 2 \mathrm{e}^{\prime}$ and $\mathrm{S}_{1} 4 \mathrm{e}^{\prime}$ intermediate levels are used, the observed MATI bands corresponding to the internal rotation of the $\mathrm{CH}_{3}$ group follow the selection rule of $\mathrm{e}^{\prime} \leftrightarrow \mathrm{e}^{\prime}$. As seen in Figure 1, the general spectral features resemble that recorded by ionizing via the $\mathrm{S}_{1} 0^{\circ}$ intermediate state. All the observed MATI bands related to the methyl torsional motion are in very good agreement with those reported by Fujii and co-workers. ${ }^{23}$ It is interesting to note that the intensities of some MATI bands

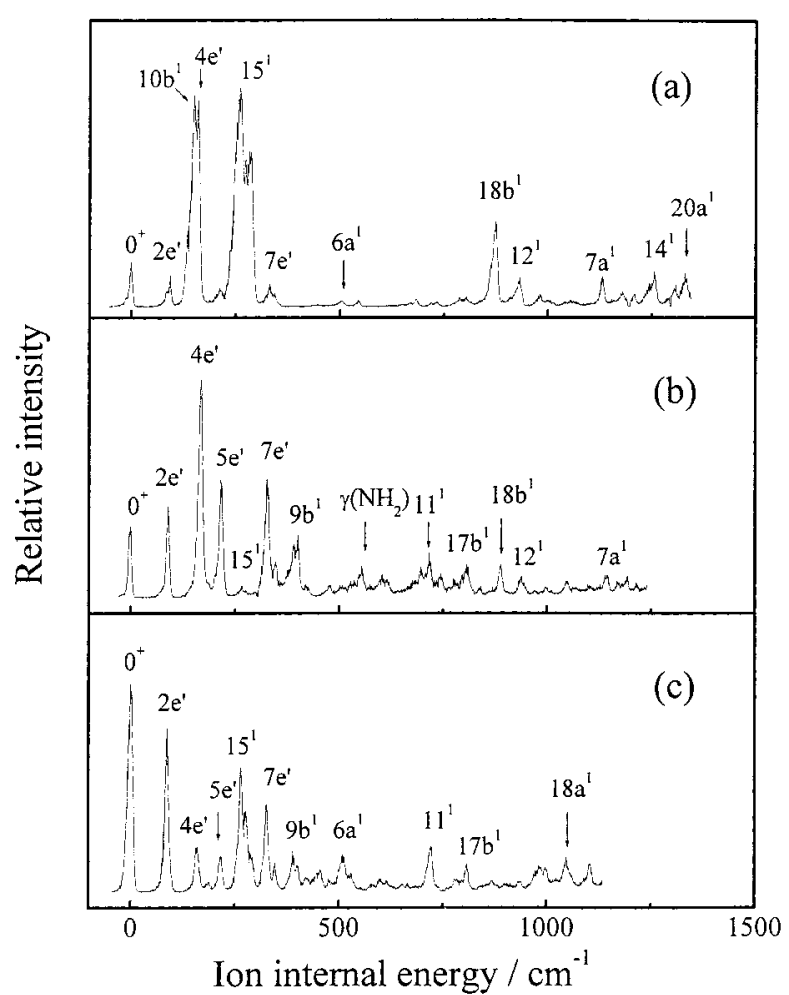

Figure 2. MATI spectra of MMA, recorded by ionizing via the (a) $\mathrm{S}_{1} 0^{\circ}$, (b) $\mathrm{S}_{1} 2 \mathrm{e}^{\prime}$, and (c) $\mathrm{S}_{1} 4 \mathrm{e}^{\prime}$ intermediate states.

corresponding to the ring vibrations are slightly increased. The pronounced bands at about 523,810, and $720 \mathrm{~cm}^{-1}$ correspond to the in-plane ring deformation $\left(6 \mathrm{a}^{1}\right.$ and $\left.12^{1}\right)$ and breathing $\left(1^{1}\right)$ vibrations, respectively, whereas that at about $650 \mathrm{~cm}^{-1}$ is related to the out-of-plane ring bending $\left(4^{1}\right)$. No band corresponding to the $\mathrm{NH}_{2}$ inversion vibration is observed. This indicates that this amino motion is little influenced by the $\mathrm{CH}_{3}$ group during the transition.

3.2. MATI Spectra of MMA. The origin of the $S_{1} \leftarrow S_{0}$ electronic transition of MMA was found to be lower than that of OMA by about $498 \mathrm{~cm}^{-1}$ by the excitation laser induced fluorescence experiments. ${ }^{14,17}$ Special care has to be taken when one records the vibronic spectra including the overlapping wavelength region. To avoid the problems caused by possible contamination, the sample-handling procedure is crucial. ${ }^{32}$ However, the species selection technique can be used when one needs to record a clean spectra of the chosen species in a mixture. ${ }^{1}$ This method involves fixing the frequency of the excitation laser to a particular intermediate state of the desired molecule while scanning the frequency of the second laser over a wide range covering the ionization threshold. It has been demonstrated that the two-color resonant two-photon MATI technique is an effective method for recording a clean spectra of the $m$-fluoroaniline (MFA) cation from a sample mixture containing MFA and $o$-fluoroaniline (OFA). ${ }^{6}$ Here, we follow the similar procedure described in our previous publications. ${ }^{6,12-13,25}$

Figure 2 displays the MATI spectra of MMA recorded by ionizing through the $0^{\circ}\left(33821 \mathrm{~cm}^{-1}\right)$ vibrationless, and the $\mathrm{CH}_{3}$ torsional $2 \mathrm{e}^{\prime}\left(33917 \mathrm{~cm}^{-1}\right)$ and $4 \mathrm{e}^{\prime}\left(34013 \mathrm{~cm}^{-1}\right)$ levels of the $S_{1}$ state. Along with a careful procedure for the calibration of the laser wavelength, analysis of the $0^{+}$bands leads to the adiabatic IE of $61059 \pm 5 \mathrm{~cm}^{-1}(7.5699 \pm 0.0006 \mathrm{eV})$ for MMA, which is in good agreement with that reported in the literature. ${ }^{23}$ The B3PW91/6-311+G** calculations predict this value to be $59606 \mathrm{~cm}^{-1}$, which is less than the measured one 
TABLE 2: Observed Bands $\left(\mathrm{cm}^{-1}\right)$ in the MATI Spectra of MMA and Possible Assignments ${ }^{a}$

\begin{tabular}{|c|c|c|c|c|}
\hline \multicolumn{3}{|c|}{ intermediate level in the $S_{1}$ state } & \multirow[b]{2}{*}{ calcd } & \multirow{2}{*}{$\begin{array}{l}\text { assignment and } \\
\text { approximate } \\
\text { description }\end{array}$} \\
\hline $0^{0}$ & $2 \mathrm{e}^{\prime}$ & $4 e^{\prime}$ & & \\
\hline 93 & $90(91)$ & $89(91)$ & $94(90)$ & $2 \mathrm{e}^{\prime}, \mathrm{CH}_{3}$ torsion \\
\hline 151 & & & 177 & $10 \mathrm{~b}^{1}, \gamma \mathrm{CN}$ \\
\hline $160(169)$ & 168 & 161 & $(171)$ & $4 \mathrm{e}^{\prime}, \mathrm{CH}_{3}$ torsion \\
\hline $220(220)$ & 216 & 219 & $(222)$ & $5 \mathrm{e}^{\prime}, \mathrm{CH}_{3}$ torsion \\
\hline 261 & 266 & 266 & 277 & $15^{1}, \beta \mathrm{CN}$ \\
\hline $283(278)$ & & & $(275)$ & $\mathrm{CH}_{3}$ torsion \\
\hline \multirow{3}{*}{$332(333)$} & 326 & 326 & $380(334)$ & $7 \mathrm{e}^{\prime}, \mathrm{CH}_{3}$ torsion \\
\hline & 401 & 392 & 411 & $9 \mathrm{~b}^{1}, \beta \mathrm{CCH}_{3}$ \\
\hline & 473 & 456 & 468 & $6 \mathrm{~b}^{1}$, ring $\beta \mathrm{CCC}$ \\
\hline 502 & & 510 & 513 & $6 \mathrm{a}^{1}$, ring $\beta \mathrm{CCC}$ \\
\hline 544 & 554 & 539 & & $\gamma \mathrm{NH}_{2}(\mathrm{wag})$ \\
\hline \multirow[t]{2}{*}{684} & 690 & & 693 & $1^{1}$, breathing \\
\hline & 713 & 719 & 756 & $11^{1}, \gamma \mathrm{CCH}_{3}$ \\
\hline 805 & 807 & 809 & 817 & $17 b^{1}$, ring $\gamma \mathrm{CH}$ \\
\hline 876 & 889 & & 880 & $18 \mathrm{~b}^{1}$, ring $\beta \mathrm{CH}$ \\
\hline \multirow[t]{3}{*}{933} & 937 & & 934 & $12^{1}$, ring $\beta$ CCC \\
\hline & 1049 & 1049 & 1064 & $18 \mathrm{a}^{1}$, ring $\beta \mathrm{CH}$ \\
\hline & & 1107 & & $9 b^{1} 11^{1}$ \\
\hline 1130 & 1146 & & 1141 & $7 \mathrm{a}^{1}, v \mathrm{CCH}_{3}$ \\
\hline 1257 & & & 1273 & $14^{1}$, ring $\nu \mathrm{CC}$ \\
\hline 1334 & & & 1325 & $20 \mathrm{a}^{1}, \nu \mathrm{CN}$ \\
\hline
\end{tabular}

${ }^{a}$ The experimental values are shifts from $61059 \mathrm{~cm}^{-1}$, whereas the calculated ones (scaled by 0.95 ) are obtained from the unrestricted B3LYP/6-311+G** calculations. $\nu, \beta$, and $\gamma$ represent stretching, inplane bending, and out-of-plane bending vibrations, respectively. The numbers in the parentheses are retrieved from ref 23.

by about $2.4 \%$. The bands related to the torsional motion of the $\mathrm{CH}_{3}$ group appear to be pronounced, as reported in the previous studies. ${ }^{23}$ Although the relative intensity is low, the good signal-to-noise ratio allows us to identify the spectral features resulting from the active ring vibrations. All of the observed bands in the MATI spectra of the MMA cation and their possible assignments are listed in Table 2. With consideration of the selection rule for the internal rotation of the $\mathrm{CH}_{3}$ group, the observed intense band at $261 \mathrm{~cm}^{-1}$ is assigned to the vibrations $15^{1}$. The MATI bands at $151,502,684,805,876$, $933,1130,1257$, and $1334 \mathrm{~cm}^{-1}$ correspond to the vibrations $10 b^{1}, 6 a^{1}, 1^{1}, 17 b^{1}, 18 b^{1}, 12^{1}, 7 a^{1}, 14^{1}$, and $20 a^{1}$, respectively. In general, the bands related to the in-plane ring deformation $\left(6 \mathrm{a}^{1}, 6 \mathrm{~b}^{1}\right.$, and $\left.12^{1}\right)$ are very weak. Many substituent-sensitive vibrations $\left(10 b^{1}, 15^{1}, 9 b^{1}, 11^{1}, 7 a^{1}\right.$, and $\left.20 a^{1}\right)$ of the MMA cation are found to be active. The weak bands at about 550 are tentatively assigned to the inversion vibration of the amino group.

3.3. MATI Spectra of PMA. Since the bands corresponding to the $\mathrm{CH}_{3}$ torsional motion of PMA in the $\mathrm{S}_{1}$ state are found to be very weak, ${ }^{14-16,21}$ the vibronic levels involving the ring vibrations in addition to the transition origin are used as the intermediate levels for the MATI experiments. Figure 3 depicts the MATI spectra of PMA recorded by ionizing through the $0^{\circ}$ (33 $\left.084 \mathrm{~cm}^{-1}\right)$ vibrationless and $15^{1}\left(33379 \mathrm{~cm}^{-1}\right)$ and $6 a^{1}$ (33 $518 \mathrm{~cm}^{-1}$ ) vibrational levels in the $S_{1}$ state. It is clear that the intensity of the $0^{+}$band in Figure $3 \mathrm{a}$ is higher than those in Figure $3 b, c$. This relative band intensity reflects the extent of the difference between the molecular geometries of the neutral and the ionic species. Because the normal modes 15 and $6 a$ are subject to certain degrees of distortion around the ring, one may expect the MATI spectra obtained via the $S_{1} 15^{1}$ and $S_{1} 6 a^{1}$ intermediate levels may lead to low intensity in the $0^{+}$band. The adiabatic IE of PMA is determined to be $60160 \pm 5 \mathrm{~cm}^{-1}$ $(7.4585 \pm 0.0006 \mathrm{eV})$, which is in good agreement with that

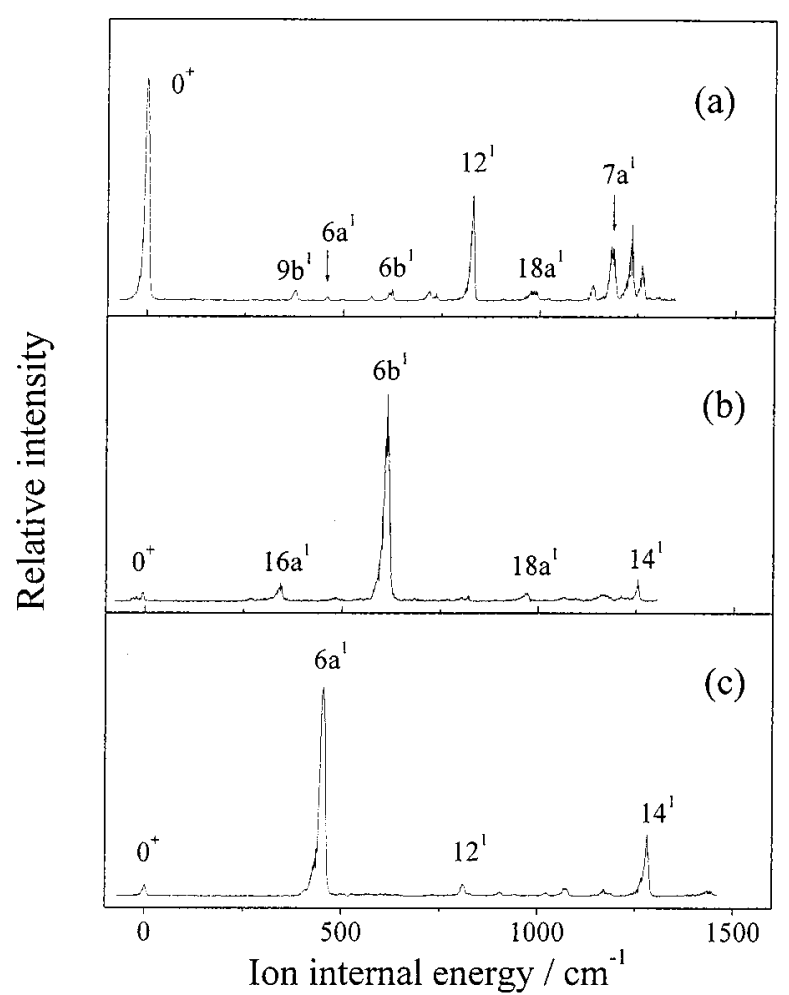

Figure 3. MATI spectra of PMA, recorded by ionizing via the (a) $\mathrm{S}_{1} 0^{\circ}$, (b) $\mathrm{S}_{1} 15^{1}$, and (c) $\mathrm{S}_{1} 6 \mathrm{a}^{1}$ intermediate states.

TABLE 3: Observed Bands $\left(\mathrm{cm}^{-1}\right)$ in the MATI Spectra of PMA and Possible Assignments ${ }^{a}$

\begin{tabular}{|c|c|c|c|c|}
\hline \multicolumn{3}{|c|}{ intermediate level in the $S_{1}$ state } & \multirow[b]{2}{*}{ calcd } & \multirow{2}{*}{$\begin{array}{l}\text { assignment and } \\
\text { approximate } \\
\text { description }\end{array}$} \\
\hline $0^{0}$ & $15^{1}$ & $6 a^{1}$ & & \\
\hline & 344 & & 352 & $16 \mathrm{a}^{1}$, ring $\gamma \mathrm{CCC}$ \\
\hline 377 & & & 391 & $9 \mathrm{~b}^{1}, \beta \mathrm{CCH}_{3}$ \\
\hline 457 & & 454 & 439 & $6 \mathrm{a}^{1}$, ring $\beta \mathrm{CCC}$ \\
\hline 570 & & & 557 & $\gamma \mathrm{NH}_{2}$ (wag) \\
\hline 624 & 615 & & 590 & $6 \mathrm{~b}^{1}, \operatorname{ring} \beta \mathrm{CCC}$ \\
\hline 718 & & & 710 & $1^{1}$, breathing \\
\hline 828 & & 814 & 794 & $12^{1}, \operatorname{ring} \beta \mathrm{CCC}$ \\
\hline 985 & 967 & & 950 & $18 \mathrm{a}^{1}$, ring $\beta \mathrm{CH}$ \\
\hline 1133 & & & 1113 & $18 \mathrm{~b}^{1}, \operatorname{ring} \beta \mathrm{CH}$ \\
\hline 1187 & 1165 & 1171 & 1188 & $7 \mathrm{a}^{1}, \nu \mathrm{CCH}_{3}$ \\
\hline 1236 & & & & $6 \mathrm{~b}^{2}$, ring $\beta \mathrm{CCC}$ \\
\hline 1262 & 1255 & 1282 & 1259 & $14^{1}$, ring $v \mathrm{CC}$ \\
\hline
\end{tabular}

${ }^{a}$ The experimental values are shifts from $60160 \mathrm{~cm}^{-1}$, whereas the calculated ones (scaled by 0.95 ) are obtained from the unrestricted B3LYP/6-311+ $\mathrm{G}^{* *}$ calculations. $\nu, \beta$, and $\gamma$ represent stretching, inplane bending, and out-of-plane bending vibrations, respectively.

reported in the literature. ${ }^{7,33}$ The B3PW91/6-311+G** calculation yields a value of $58560 \mathrm{~cm}^{-1}$, which underestimates by about $2.7 \%$.

When the $\mathrm{S}_{1} 0^{\circ}$ vibrationless state is used as the intermediate level, many vibrations of the ion are found to be active, as shown in Figure 3a. Table 3 lists all of the observed bands in the MATI spectra of the PMA cation and their possible assignments. The strong band at $828 \mathrm{~cm}^{-1}$ results from the in-plane ring deformation $12^{1}$, whereas the moderately intense bands at 1187 , 1236, and $1262 \mathrm{~cm}^{-1}$ correspond to the $7 \mathrm{a}^{1}, 6 \mathrm{~b}^{2}$, and $14^{1}$ vibrations of the PMA cation, respectively. Figure $3 \mathrm{~b}$ shows the MATI spectrum acquired by ionizing through the $\mathrm{S}_{1} 15^{1}$ vibronic level. Since the molecule exhibits the in-plane $\mathrm{C}-\mathrm{NH}_{2}$ and $\mathrm{C}-\mathrm{CH}_{3}$ bending as well as the ring vibrations in the intermediate state, only a few active vibrations can be observed for this molecule in the cationic state. ${ }^{25,27}$ The only intense band 
at $615 \mathrm{~cm}^{-1}$ is assigned to the $6 \mathrm{~b}^{1}$ vibration of the cation. The weak bands at $344,967,1165$, and $1255 \mathrm{~cm}^{-1}$ are related to vibrations $16 \mathrm{a}^{1}, 18 \mathrm{a}^{1}, 7 \mathrm{a}^{1}$, and $14^{1}$, respectively. In the case that the $\mathrm{S}_{1} 6 \mathrm{a}^{1}$ state is used as the intermediate level, the most intense band in the MATI spectrum corresponds to the $6 \mathrm{a}^{1}$ vibration of the cation. The moderately intense band at $1282 \mathrm{~cm}^{-1}$ results from the in-plane ring stretching $14^{1}$, whereas the weak bands at 814 and $1171 \mathrm{~cm}^{-1}$ are related to the in-plane ring deformation $12^{1}$ and $\mathrm{C}-\mathrm{CH}_{3}$ stretching $7 \mathrm{a}^{1}$ vibrations, respectively.

\section{Discussion}

4.1. Vicinal Substitution Effect on Molecular Structure and Large Amplitude Motions. Although the gas-phase experimental data are not yet available, the structures of OMA, MMA, and PMA in the $S_{0}$ and $S_{1}$ states have been investigated by ab initio calculations. ${ }^{16,17,22}$ We have performed the unrestricted $\mathrm{HF} / 6-311+\mathrm{G}^{* *}$ calculations to predict the molecular geometries of these species in the cationic state. These results show that the aromatic ring is distorted from a regular hexagon, as that in benzene. In particular, the endocyclic angles at the substitution positions are slightly deviated from $120^{\circ}$, resulting from the steric and electronic effects of the amino and methyl groups.

For all of these structural isomers in the $\mathrm{S}_{0}$ state, the amino part has a somewhat $\mathrm{sp}^{3}$ hybridization-like character due to the presence of the lone-pair electrons on the nitrogen. The degree of nonplanarity of the amino group $(\Phi)$ may be defined as the angle between the bisector of the $\mathrm{HNH}$ angle and the extension of the $\mathrm{C}-\mathrm{NH}_{2}$ bond. The angle $\Phi$, which is often referred to as the angle between the plane of the ring and the $\mathrm{NH}_{2}$ group, is determined to be $42^{\circ}$ for these three species, as in the case of aniline. ${ }^{34}$ Although the presence of a $\mathrm{CH}_{3}$ group at a different relative position of the ring does not affect the nonplanarity of the $\mathrm{NH}_{2}$ group, it can influence the interaction between the ring and the amino substituent. The barriers to the inversion vibration (referred to as large amplitude motion) of the $\mathrm{NH}_{2}$ group have been determined to be $558,528,588$, and $526 \mathrm{~cm}^{-1}$, respectively, for OMA, MMA, PMA, and aniline in the $\mathrm{S}_{0}$ state. ${ }^{35,36}$ A larger barrier to planarity implies a higher electron density on the nitrogen atom of the amino group.

The interaction between the methyl group and the aromatic ring may result from (1) the inductive effect through the $\sigma$ bond and (2) the hyperconjugation through the $\pi$ orbitals, leading to a change in the zero-point level. The inductive effect is related to the ability of withdrawing or donating electrons, whereas the resonance effect reflects the extent of the $\pi$ overlaps between the $\mathrm{CH}_{3}$ group and the ring. To quantify the extent of each effect is nontrivial particularly for an electronic transition involving a significant geometry change. Previous theoretical investigations on toluene showed that the hyperconjugation is more important than the electron-donating character. ${ }^{37}$ In addition, the hyperconjugation between the $\mathrm{CH}_{3}$ substituent and the ring gives rise to an increased electron density in the ortho and para positions more than in the meta position. This argument is consistent with the reported $\mathrm{NH}_{2}$ inversion barrier with the order: aniline $<$ MMA $<$ OMA $<$ PMA.

Concerning the second large amplitude motion in methylaniline, the internal rotation of the $\mathrm{CH}_{3}$ group is closely related to the nearby $\pi$-electron density. In addition, it can be influenced by the $\mathrm{NH}_{2}$ group to a certain extent, depending on the relative location in the ring. The energy barriers to the $\mathrm{CH}_{3}$ internal rotation have been determined to be $703,9,6$, and $5 \mathrm{~cm}^{-1}$, respectively, for OMA, MMA, PMA, and toluene in the $\mathrm{S}_{0}$ state. ${ }^{14,20,38}$ The large barrier height associated with OMA may result from the steric hindrance due to the nearby $\mathrm{NH}_{2}$ group. ${ }^{14,16}$
TABLE 4: Measured Electronic Transition and Ionization Energies $\left(\mathrm{cm}^{-1}\right)$ of Aniline, OMA, MMA, and PMA

\begin{tabular}{lcrrrrr}
\hline molecule & $\mathrm{S}_{1} \leftarrow \mathrm{S}_{0}$ & $\delta\left(\mathrm{S}_{1} \leftarrow \mathrm{S}_{0}\right)$ & ion $\leftarrow \mathrm{S}_{1}$ & $\delta\left(\right.$ ion $\left.\leftarrow \mathrm{s}_{1}\right)$ & IE & $\delta(\mathrm{IE})$ \\
\hline aniline $^{a}$ & 34029 & 0 & 28242 & 0 & 62271 & 0 \\
OMA & 34318 & 289 & 26684 & -1588 & 61002 & -1269 \\
MMA & 33832 & -197 & 27227 & -1015 & 61059 & -1212 \\
PMA & 33084 & -945 & 27076 & -1166 & 60160 & -2111
\end{tabular}

${ }^{a}$ Reference 13 .

It is generally known that the $\mathrm{S}_{1} \leftarrow \mathrm{S}_{0}$ transition of benzene derivatives corresponds to the $\pi \pi^{*}$ electronic excitation, leading to an expansion in the ring and a significant change in overall molecular geometry. The configuration interaction singles (CIS) calculations with the $6-31+\mathrm{G}^{*}$ or larger basis sets predict that the angle $\Phi$ is zero for OMA, MMA, and PMA. It follows that the strong $\pi$-electron overlap between the ring and the amino group causes these methylanilines to exhibit quinoid-like resonance character as that in aniline in the $S_{1}$ state. ${ }^{16,22,34}$ The calculated results also suggest that the interaction between the $\mathrm{NH}_{2}$ and the ring is stronger than the $\mathrm{CH}_{3}$ substituent. For OMA in the $\mathrm{S}_{1}$ state, the $\mathrm{CH}_{3}$ and $\mathrm{NH}_{2}$ substituents are repelled further apart from each other. The hindrance of the $\mathrm{CH}_{3}$ rotation by the intrinsic through-space interaction with the $\mathrm{NH}_{2}$ is substantially reduced, resulting in a smaller energy barrier to the $\mathrm{CH}_{3}$ torsion. The energy barriers to the $\mathrm{CH}_{3}$ internal rotation were found to be $40,317,44$, and $25 \mathrm{~cm}^{-1}$, respectively, for OMA, MMA, PMA, and toluene in the $S_{1}$ state. ${ }^{14,20,23,38}$ The relatively large barrier height in MMA indicates that the $\pi$-electron density near the $\mathrm{CH}_{3}$ group is increased due to the enhanced hyperconjugation with the ring.

The barriers to the $\mathrm{CH}_{3}$ internal rotation in the OMA and MMA cations are determined to be 649 and $248 \mathrm{~cm}^{-1}$, respectively, by PFI-ZEKE spectroscopy. ${ }^{23}$ Upon the transition from the $S_{1}$ to the ionic state, the change in the barrier height reflects the change of the $\pi$-electron density around the ring near the $\mathrm{CH}_{3}$ group. It is also closely related to the relative position of the two substituents and the nature of the electronic state. Although there are still no data available, the energy barrier of the $\mathrm{CH}_{3}$ rotation in the PMA cation is expected to be lower than those in the OMA and MMA cations.

4.2. Vicinal Effect on Electronic Transition and Ionization. The origins of the $\mathrm{S}_{1} \leftarrow \mathrm{S}_{0}$ electronic transition of aniline, OMA, MMA, and PMA are reported to be $34029,34318,33832$, and $33084 \mathrm{~cm}^{-1}$, respectively. ${ }^{14-22}$ As mentioned in a previous section, the excitation is mainly subject to a $\pi \pi^{*}$ transition, giving rise to a significant change in the $\pi$-electron density around the ring. The observation of the difference in the transition energy reflects the degree of the change in the $\pi$-electron density of the aromatic ring upon electronic excitation. When the $\mathrm{CH}_{3}$ is at the para position with respect to the $\mathrm{NH}_{2}$ group, the collective interaction between the ring and the two substituents is optimized, leading to a red shift in the excitation energy by $945 \mathrm{~cm}^{-1}$ with respect to that of aniline.

The recent R2PI and MATI experimental studies show that the $S_{1} \leftarrow S_{0}$ electronic excitation mainly occurs around the ring whereas the transition from the neutral $S_{1}$ to the cationic state corresponds to the removal of one of the lone-pair electrons of nitrogen. ${ }^{13}$ Although no experimental result has been reported, similar processes are expected for the electronic transition of methylanilines. The respective adiabatic IEs of aniline, OMA, MMA, and PMA have been determined to be 62 271, 61002 , 61059 , and $60160 \mathrm{~cm}^{-1}$, as listed in Table 4. This indicates that when the $\mathrm{CH}_{3}$ substitutent is at the para position with respect 
TABLE 5: Frequencies $\left(\mathrm{cm}^{-1}\right)$ of the Observed Vibrations of OMA, MMA, and PMA in the Cationic Ground State

\begin{tabular}{|c|c|c|c|c|c|c|c|c|}
\hline \multicolumn{2}{|c|}{ aniline $^{a}$} & \multicolumn{2}{|c|}{ OMA } & \multicolumn{2}{|c|}{ MMA } & \multicolumn{2}{|c|}{ PMA } & \multirow[b]{2}{*}{ normal vibration } \\
\hline $\exp$ & calc & $\exp$ & calc & $\exp$ & calc & $\exp$ & calc & \\
\hline & & 401 & 406 & 401 & 411 & 377 & 391 & $9 \mathrm{~b}^{1}, \operatorname{ring} \beta\left(\mathrm{CCH}_{3}\right)$ \\
\hline & & 506 & 477 & 464 & 468 & 624 & 590 & $6 \mathrm{~b}^{1}$, ring $\beta(\mathrm{CCC})$ \\
\hline 522 & 521 & 544 & 548 & 506 & 513 & 457 & 439 & $6 \mathrm{a}^{1}$, ring $\beta(\mathrm{CCC})$ \\
\hline 814 & 814 & 720 & 695 & 687 & 693 & 718 & 710 & $1^{1}$, breathing \\
\hline \multirow[t]{2}{*}{982} & 979 & 811 & 807 & 933 & 934 & 821 & 828 & $12^{1}, \operatorname{ring} \beta(\mathrm{CCC})$ \\
\hline & & 1148 & 1149 & 1138 & 1141 & 1187 & 1188 & $7 \mathrm{a}^{1}$, ring $v\left(\mathrm{CCH}_{3}\right)$ \\
\hline
\end{tabular}

${ }^{a}$ Reference 6.

to the $\mathrm{NH}_{2}$ group, the combined interaction between the ring and the two substituents is maximized, leading to a red shift of $2111 \mathrm{~cm}^{-1}$.

4.3. Vicinal Effect on Molecular Vibration. For the OMA, MMA, and PMA cations, there are 45 normal vibrations that include 30 benzene-like, 6 amino, and 9 methyl modes. Up to now, only the internal rotations of the $\mathrm{CH}_{3}$ group of the OMA and MMA cations have been studied. ${ }^{23}$ The present experiments provide new experimental data on the active vibrations of these three structural isomers of methylaniline, as shown in Figures $1-3$. Similar to that found in cases of other disubstituted benzenes, ${ }^{4-6,25-28}$ the breathing as well as the in-plane ring deformation vibrations appears in the MATI spectra of three structural isomers. As shown in Table 5, the frequencies of the breathing vibration $\left(1^{1}\right)$ are found to be $720,687,718$, and 814 $\mathrm{cm}^{-1}$ for the OMA, MMA, PMA, and aniline cations. The lower frequency by more than $94 \mathrm{~cm}^{-1}$ in these methyanilines results from the presence of the methyl group in the ring. Furthermore, there is a difference of less than $33 \mathrm{~cm}^{-1}$ in the frequency of this mode among these three methylaniline cations. Similar observation is found for normal vibration 12, with the frequencies of $811,933,821$, and $982 \mathrm{~cm}^{-1}$ for the OMA, MMA, PMA, and aniline cations. However, mode 12 mainly involves an inplane trigonal $\mathrm{CCC}$ bending vibration, where the ring carbon $\mathrm{C}_{1}, \mathrm{C}_{3}$, and $\mathrm{C}_{5}$ atoms move as a group in one direction and the $\mathrm{C}_{2}, \mathrm{C}_{4}$, and $\mathrm{C}_{6}$ atoms in an opposite way. For MMA, the amino and methyl substituents are attached to the $\mathrm{C}_{1}$ and $\mathrm{C}_{3}$ atoms, respectively. The observed difference in the frequency of mode 12 among these structural isomers of methylaniline reflects the extent of the coupling between the ring skeletal (CCC bending) and the substituent-sensitive $\left(\mathrm{C}-\mathrm{NH}_{2}\right.$ and $\left.\mathrm{C}-\mathrm{CH}_{3}\right)$ stretching vibrations.

The frequencies of normal vibration $6 \mathrm{a}$ are 544, 506, and $457 \mathrm{~cm}^{-1}$, whereas those of $6 \mathrm{~b}$ are 506,464 , and $624 \mathrm{~cm}^{-1}$ for the OMA, MMA, and PMA cations, respectively. Although both the $6 \mathrm{a}$ and $6 \mathrm{~b}$ modes mainly involve the in-plane ring deformation, they differ slightly in the vibrational patterns. The frequency of $6 \mathrm{a}$ is greater than that of $6 \mathrm{~b}$ for the ortho and meta isomers, whereas it goes opposite for the $p$-methylaniline. A similar finding has be reported for the $o-, m-$, and $p$-fluoroaniline cations. ${ }^{4-6}$ It is interesting to note that the $\mathrm{C}-\mathrm{CH}_{3}$ bending $\left(9 \mathrm{~b}^{1}\right)$ and stretching $\left(7 \mathrm{a}^{1}\right)$ vibrations are active. The frequencies of mode $9 \mathrm{~b}$ are 401,401 , and $377 \mathrm{~cm}^{-1}$, whereas those of mode $7 \mathrm{a}$ are 1148,1138 , and $1187 \mathrm{~cm}^{-1}$ for the OMA, MMA, and PMA cations, respectively.

\section{Conclusion}

The MATI spectra of OMA, MMA, and PMA have been recorded by ionizing via various intermediate levels of their $S_{1}$ states. The adiabatic IEs of these three structural isomers are determined to be $61002 \pm 5,61059 \pm 5$, and $60160 \pm 5 \mathrm{~cm}^{-1}$, respectively. The low-frequency bands corresponding to the $\mathrm{CH}_{3}$ internal rotation dominate in the MATI spectra of OMA and MMA; nevertheless none is found in that of PMA. This observation indicates that both the nature of the substitutents and the relative location in the ring can influence the electronic transition.

The active vibrations of the OMA, MMA, and PMA cations are reported for the first time. The frequencies of some observed vibrations are found to vary slightly among these structural isomers. This frequency difference may result from (1) the nature of the substituents, (2) the relative location of the substituents at the ring, (3) the pattern of the normal, and (4) the extent of the substituents participated in the overall vibration. The present experimental results are well supported by ab initio and density functional theory calculations.

Acknowledgment. We gratefully acknowledge financial support from the National Science Council of the Republic of China under Grant Number NSC-90-2113-M-001-038.

\section{References and Notes}

(1) Schlag, E. W. Zeke Spectroscopy; Cambridge University Press: Cambridge, U.K., 1998.

(2) Hollas, J. M. Chem. Soc. Rev. 1993, 22, 371.

(3) Laane, J. Annu. Rev. Phys. Chem. 1994, 45, 179.

(4) Tzeng, W. B.; Lin, J. L. J. Phys. Chem. A 1999, 103, 8612.

(5) Lin, J. L.; Tzeng, W. B., Phys. Chem. Chem. Phys. 2000, 2, 3759. 120.

(6) Lin, J. L.; Lin, K. C.; Tzeng, W. B. Appl. Spectrosc. 2001, 55,

(7) The NIST Chemistry Webbook, http://webbook.nist.gov/, and references therein.

(8) Müller-Dethlefs, K.; Sander, M.; Schlag, E. W. Chem. Phys. Lett. 1984, 112, 291.

(9) Zhu, L.; Johnson, P. M. J. Chem. Phys. 1991, 94, 5769.

(10) Dessent, C. E. H.; Haines, S. R.; Müller-Dethlefs, K. Chem. Phys. Lett. 1999, 315, 103.

(11) Lembach, G.; Brutschy, B. Chem. Phys. Lett. 1997, 273, 421.

(12) Lin, J. L.; Tzeng, W. B. J. Chem. Phys. 2000, 113, 4109.

(13) Lin, J. L.; Tzeng, W. B. J. Chem. Phys. 2001, 115, 743.

(14) Okuyama, K.; Mikami, N.; Ito, M. Laser Chem. 1987, 7, 197.

(15) Disselkamp, R.; Im, H. S.; Bernstein, E. R. J. Chem. Phys. 1992, 97, 7889 .

(16) Tzeng, W. B.; Narayanan, K.; Lin, J. L.; Tung, C. C. Spectrochim. Acta A 1999, 55, 153.

(17) Santos, L.; Martinez, E.; Ballesteros, B.; Sanchez, J. Spectrochim. Acta A 2000, 56, 1905

(18) Powers, D. E.; Hopkins, J. B.; Smalley, R. E. J. Chem. Phys. 1980, 72,5721 .

(19) Yan, S.; Spangler, L. H. J. Chem. Phys. 1992, 96, 4106.

(20) Tan, X. Q.; Pratt, D. W. J. Chem. Phys. 1994, 100, 7061.

(21) Tembreull, R.; Dunn, T. M.; Lubman, D. M. Spectrochim. Acta A 1986, $42,899$.

(22) Tzeng, W. B.; Narayanan, K. J. Mol. Struct. 1998, 446, 93.

(23) Ikoma, H.; Takazawa, K.; Emura, Y.; Ikeda, S.; Abe, H.; Hayashi, H.; Fujii, M. J. Chem. Phys. 1996, 105, 10201.

(24) Frisch, M. J.; Trucks, G. W.; Schlegel, H. B.; Scuseria, G. E.; Robb, M. A.; Cheeseman, J. R.; Zakrzewski, V. G.; Montgomery, J. A., Jr.; Stratmann, R. E.; Burant, J. C.; Dapprich, S.; Millam, J. M.; Daniels, A. D.; Kudin, K. N.; Strain, M. C.; Farkas, O.; Tomasi, J.; Barone, V.; Cossi, M.: Cammi, R.; Mennucci, B.; Pomelli, C.; Adamo, C.; Clifford, S.; Ochterski, J.; Petersson, G. A.; Ayala, P. Y.; Cui, Q.; Morokuma, K.; Malick, D. K.; Rabuck, A. D.; Raghavachari, K.; Foresman, J. B.; Cioslowski, J.; Ortiz, J. V.; Baboul, A. G.; Stefanov, B. B.; Liu, G.; Liashenko, A.; Piskorz, P.; Komaromi, I.; Gomperts, R.; Martin, R. L.; Fox, D. J.; Keith, T,; AlLaham, M. A.; Peng, C. Y.; Nanayakkara, A.; Gonzalez, C.; Challacombe, M.; Gill. P. M. W.; Johnson, B.; Chen, W.; Wong, M. W.; Andres, J. L.; Gonzalez, C.; Head-Gordon, M.; Replogle, E. S.; Pople, J. A. Gaussian 98, Revision A.7; Gaussian, Inc.: Pittsburgh, PA, 1998.

(25) Lin, J. L.; Huang, L. C. L.; Tzeng, W. B. J. Phys. Chem. A 2001, 105,11455 .

(26) Gerhards, M.; Unterberg, C.; Schumm, S. J. Chem. Phys. 1999, $111,7966$.

(27) Huang, L. C. L.; Lin, J. L.; Tzeng, W. B. Chem. Phys. 2000, 261, 449.

(28) Lin, J. L.; Wu, R. H.; Tzeng, W. B. Chem. Phys. Lett. 2002, 353, 
(29) Boogaarts, M. G. H.; Holleman, I.; Jongma, R. T.; Parker, D. H.; Meijer, G.; Even, U. J. Chem. Phys. 1996, 104, 4357.

(30) Chupka, W. A. J. Chem. Phys. 1993, 98, 4520.

(31) Varsanyi, G. Assignments of Vibrational Spectra of Seven Hundred Benzene Derivatives; Wiley: New York, 1974.

(32) Tzeng, W. B.; Narayanan, K.; Hsieh, C. Y.; Tung, C. C. J. Chem. Soc., Faraday Trans. 1997, 93, 2981.
(33) Zhang, X.; Knee, J. L. Faraday Discuss. 1994, 97, 299.

(34) Tzeng, W. B.; Narayanan, K.; Shieh, K. C.; Tung, C. C. J. Mol. Struct. 1998, 428, 231

(35) Kydd, R. A.; Krueger, P. J. J. Chem. Phys. 1980, 72, 280.

(36) Quack, M.; Stockburger, M. J. Mol. Spectrosc. 1972, 43, 87.

(37) Libit, L.; Hoffman, R. L. J. Am. Chem. Soc. 1974, 96, 1370.

(38) Lu, K. T.; Eiden, G. C.; Weisshaar, J. C. J. Phys. Chem. 1992, 96, 9742. 